\title{
A rare case of iii cranial nerve palsy - mucormycosis involving the right maxillary and ethmoidal sinus
}

\author{
Gandhi K. ${ }^{1 *}$, Sakthivel V. ${ }^{2}$ \\ DOI: https://doi.org/10.17511/ijmrr.2021.i03.08 \\ 1* K. Praveen Gandhi, Post Graduate, Department of Medicine, Vinayaka Mission's Medical College and Hospital, Vinayaka Mission's \\ Research Foundation (Deemed to be University) Karaikal, Puducherry, , India. \\ 2 V. Sakthivel, Professor, Department of Medicine, Vinayaka Mission's Medical College and Hospital, Vinayaka Mission's Research Foundation \\ (Deemed to be University) Karaikal, Puducherry, , India.
}

III $^{\text {rd }}$ Cranial nerve palsy, known as oculomotor nerve palsy, may result from various causes, however, the etiology remains unknown in some instances. This case report aims to present the authors' experience with a case of III ${ }^{\text {rd }}$ cranial nerve palsy, together with a review of the literature. Many etiologies have been associated with isolated oculomotor nerve palsies. We report the case of a patient who presented with right maxillary and ethmoidal sinusitis with III $^{\text {rd }}$ cranial nerve palsy associated with mucormycosis. Careful examinations to rule out other causes must be done and then treatment with antifungals should be considered after early diagnosis.

Keywords: Cranial nerve III palsy, Maxillary sinus, Ethmoidal sinus, Mucormycosis

\section{Corresponding Author}

K. Praveen Gandhi, Post Graduate, Department of Medicine, Vinayaka Mission's Medical College and Hospital, Vinayaka Mission's Research Foundation (Deemed to be University) Karaikal, Puducherry, , India.

Email: praveen.abtj161293@gmail.com
How to Cite this Article

To Browse

Gandhi KP, Sakthivel V. A rare case of iii cranial nerve palsy - mucormycosis involving the right maxillary and ethmoidal sinus. Int J Med Res Rev. 2021;9(3):181-184.

Available From

https://ijmrr.medresearch.in/index.php/ijmrr/article/ view/1285

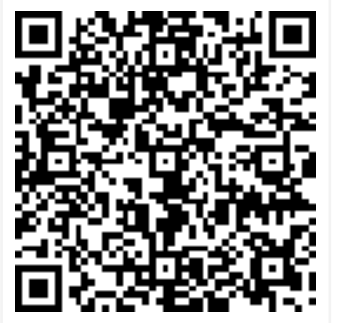

Manuscript Received 2021-05-14

Conflict of Interest No
Review Round 1 2021-05-24

Funding
Review Round 2 2021-06-05

Ethical Approval Yes

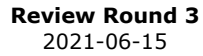

Plagiarism X-checker $8 \%$
Accepted 2021-06-18

Note

(c) 2021 by K. Praveen Gandhi, V. Sakthivel and Published by Siddharth Health Research and Social Welfare Society. This is an Open Access article licensed under a Creative Commons Attribution 4.0 International License 


\section{Background information}

A cranial nerve palsy may cause a complete or partial weakness or paralysis of the areas served by the affected nerve. In the case of a cranial nerve that has multiple functions (such as the oculomotor nerve), a palsy can affect all of the various functions or only some of the functions of that nerve. Usually, the third, fourth, and sixth cranial nerves participate in eyeball movement by extraocular muscle control. Acquired palsy of these nerves can result from various causes such as trauma, vascular disease, intracranial tumors, or aneurysm, and so on.

The largest report from the Mayo Clinic, which included 4278 patients over 30 years, identified sixth nerve palsy and undetermined cause as having the highest prevalence. In advanced disease chemosis, ptosis, proptosis, ophthalmoplegia and blindness and multiple cranial nerve function may be lost or impaired [1]. A meticulous history, detailed workup, confirmation of diagnosis by histopathology and culture helps to make a diagnosis. Aggressive management of these patients can reverse the adverse outcome. Prognosis is directly related to the length of time before diagnosis and treatment [2].

In parallel, mucormycosis, a rare opportunistic invasive fungal infection, is known to be fatal and aggressive. Mucormycosis is a term used to refer to any fungal infections of the order Mucorales, which belongs to class Zygomycetes. Rhinocerebreal mucormycosis is a rare but fatal infection of the nasal cavity and sinuses. The incidence of mucormycosis is approximately 1.7 cases per $1,000,000$ inhabitants per year [3]. Mucormycosis rarely affects otherwise healthy people. It is a disease of patients with a pre-existing debilitating disease (diabetes mellitus) or is receiving immunosuppressive therapy. It is characterized by an aggressive necrotizing infection spreading from the nose to the paranasal sinuses, orbit, and brain. This disease is most often associated with diabetics but can be seen with Chronic Kidney disease, leukemia, malnutrition, AIDS, steroid, antimetabolic or antibiotic therapy, severe burn, septicemia, and treatment with immunosuppressive medications. Early clinical recognition of this potentially fatal disease is essential before irreversible changes occur $[4,5]$.

We describe the case of a 60-year-old female patient who suffered complications of rhinocerebral mucormycosis while she was hospitalized.
We present a case of Mucormycosis involving the right Maxillary and ethmoidal sinus and discuss the literature on its early signs and symptoms, pathophysiology, and treatment options.

\section{Case details}

The 60-year-old lady known case of Type 2 diabetes mellitus came with complaints of right side ptosis, ophthalmoplegia, chemosis of the right eye and right-sided nasal discharge for the past 10 days. Routine investigations showed elevated blood glucose levels with an HbA1C of $9 \%$. All other investigations were normal. MRI brain shows mucosal opacification of the right maxillary sinus and right posterior ethmoidal air cells. Bilateral $(R>L)$ diffuse optic nerve swelling. Myositis changes involving right superior oblique and medial rectus muscles with adjacent periorbital fat stranding were recorded. These features may be due to uncontrolled diabetes but can also be related to fungal sinusitis with right intraorbital extension.

CT scan of brain: Cerebellum, fourth ventricle, brain stem appear normal. Right maxillary and ethmoidal sinusitis with septal deviation to the right. Basal cisterns, suprasellar region appear normal. Basal ganglia and internal capsule appear normal. Sylvian fissures, III \& lateral ventricles appear normal. Cerebral hemispheres are normal. Sulci and gyri are normal. No midline shift and no focal edema. Bony calvarium normal.

The $\mathrm{KOH}$ mount of the Nasal secretions showed evidence of broad sparsely septate fungal hyphae and on Sabouraud dextrose agar the isolate was identified as Rhizopus oryzae. The patient was started on Inj.Amphotericin B (50 mg/day) for 2 weeks. At last, after resolution of maxillary and ethmoidal sinusitis there was an improvement in the ptosis and ophthalmoplegia and the patient was discharged.

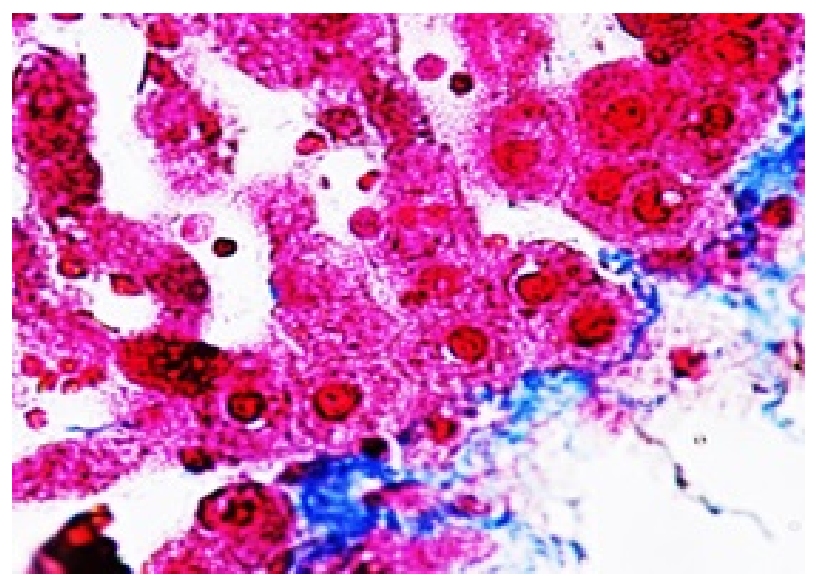


Figure-1: Histopathology smear showing broad non septate hyphae of Mucor

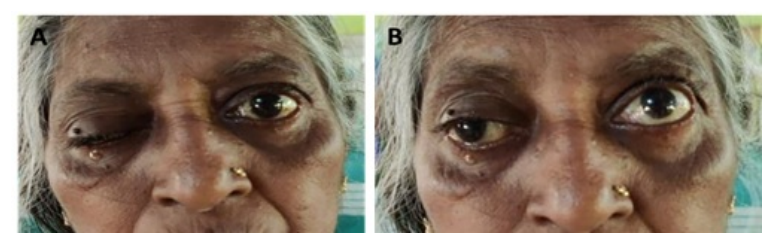

Figure 2 -A-before initiation of amphotericin B - after initiation of amphotericin

\section{Discussion}

The fungal infection in a diabetic and immunosuppressed individual leads to fatal nasal Sinusitis, orbit and skull invasion of the patients. The incidence of this uncommon disease is uncertain; only 500 instances were found during a study of the literature between 1970 and 2020 [6]. The sickness was regarded as generally deadly and untreatable almost the following decade after Gregory et al. initially described it in US literature in the year 1943. Fungi from the Mucorales family Mucoraceae, most frequently from the Rhizopus, Mucor and Absidian genera are /responsible for Mucormycosis [7]. Cultivated by oral and nasal mucosa of humans without disease, Mucorales spores are all-round in nature and frequently present in bread, soil and fruit. Various kinds of human mucosal infection are recognized: pulmonary, cutaneous, gastrointestinal, central nervous system (CNS) [8]. The RCM is of particular importance for emergency doctors since it may be misdiagnosed with sinusitis, ocular cellulitis, cavernous sinus thrombosis and viral illness. Its survival rate is also linked, as explained below, to early diagnosis [9]. Moreover, mild anaemia is usually seen with aneutrophilic leucocytosis. Fungal Hyphae, aseptate, 90-degree branching, irregularly large and necrosis and haemorrhaging zones, are shown in the microscopic exam. Necrosis, polymorphonuclear infiltration, multinucleated giant cells and aseptate hyphae are present. Patients frequently experience facial and orbital discomfort, loss of vision and widespread swelling on the afflicted side. In individuals with mucormycosis multiple cranial nerve paralysis is also recorded. [10]. The CT of the sinuses showing oedema, the filling fluid in the ethmoid sinuses and periorbital tissue damage and borders are part of diagnostic imaging. Standard medical treatment based on clinical response and degree of nephrotoxicity is amphotericin B at $1-5 \mathrm{mg} / \mathrm{kg} /$ day for 4 weeks.
Due to its lower nephrotoxicity, the lipid formulation of amphotericin B can be administered at a larger dose and for more duration. Posaconazole is an alternative treatment of choice in recalcitrant individuals with infections resistant to amphotericin $B$ [11]. It mainly functions as a cytochrome inhibitor for P-450 3A4. Although the prevalence of facial nerve paralysis is 11 per cent, it is a critical clinical symptom, requiring rapid treatment of diabetes condition, surgical degradation and adequate antifungal medication in uncontrolled diabetic patients with mucormycosis. However, the cranial nerve function showed partial improvement in the form of improved eye closure, reduced facial asymmetry at rest although the grading was the same. As per the reported findings in the literature, recovery after grade IV facial nerve paralysis will start from the fourth month onwards[12,13]. Physicians should be aware of such atypical clinical presentations. This would facilitate the implementation of an early appropriate medical and surgical treatment. Such a treatment regimen would aid disease recovery and a better prognosis.

\section{Conclusion}

Rhinocerebral mucormycosis remains a poorly understood disease with a high mortality rate. Presently, the triad of clinician's awareness, prompt initiation of treatment and timely surgical intervention represent the effective way of managing the disease. Clinical suspicion and prompt treatment are fundamental to realize the cure of the disease.

\section{Reference}

01. Schumacher-Feero LA, Yoo KW, Solari FM, Biglan AW. Third cranial nerve palsy in children. Am J Ophthalmol. 1999 Aug;128(2)216-21. doi: 10.1016/s0002-9394(99)00128-2 [Crossref] [PubMed][Google Scholar]

02. Berger PS, Bataini JP. Radiation-induced cranial nerve palsy. Cancer. 1977 Jul;40(1)152-5. doi: 10.1002/1097-0142(197707)40:1<152: :aid-

cncr2820400125>3.0.co;2-e [Crossref][PubMed] [Google Scholar]

03. Akagi T, Miyamoto K, Kashii S, Yoshimura N. Cause and prognosis of neurologically isolated third, fourth, or sixth cranial nerve dysfunction in cases of oculomotor palsy. Jpn J Ophthalmol. 2008 JanFeb;52(1)32-5. doi: 10.1007/s10384-007-0489-3 [Crossref][PubMed][Google Scholar] 
04. Addlestone RB, Baylin GJ. Rhinocerebral mucormycosis. Radiology. 1975 Apr;115(1)113-7. doi: 10.1148/115.1.113 [Crossref][PubMed][Google Scholar]

05. Garlapati K, Chavva S, Vaddeswarupu RM, Surampudi J. Fulminant mucormycosis involving paranasal sinuses- a rare case report. Case Rep Dent. 2014;465919. doi: 10.1155/2014/465919 [Crossref][PubMed][Google Scholar]

06. Therakathu J, Prabhu S, Irodi A, Sudhakar S V, Yadav $V$ K. Imaging features of rhinocerebral mucormycosis- A study of 43 patients. The Egyptian Journal of Radiology and Nuclear Medicine. 2018;49(2)447-452. [Crossref][PubMed][Google Scholar]

07. Cohen SG, Greenberg MS. Rhinomaxillary mucormycosis in a kidney transplant patient. Oral Surg Oral Med Oral Pathol. 1980 Jul;50(1)33-8. doi: 10.1016/0030-4220(80)90328-x [Crossref] [PubMed][Google Scholar]

08. Shekar V, Sikander J, Rangdhol V, Naidu M. Facial nerve paralysis- $A$ case report of rare complication in uncontrolled diabetic patient with mucormycosis. J Nat Sci Biol Med. 2015 JanJun;6(1)226-8. doi: 10.4103/0976-9668.149195 [Crossref][PubMed][Google Scholar]
09. Shah V, Ganapathy H, Gopalakrishnan R, Geetha NA. rare case of facial palsy due to mucormycosis. International Journal of Otolaryngology and Head \& Neck Surgery. 2015;4(3)224. [Crossref][PubMed] [Google Scholar]

10. Ferry AP, Abedi S. Diagnosis and management of rhino-orbitocerebral mucormycosis (phycomycosis)- A report of 16 personally observed cases. Ophthalmology. 1983 Sep;90(9)1096-104. doi: 10.1016/s0161-6420(83)80052-9 [Crossref] [PubMed][Google Scholar]

11. Rajeshwari A, S K S Gangadhara. "Rhinocerebral mucormycosis- an unusual presentation". Am J Med Med Sci. 2012;2(1)16-9. [Crossref][PubMed] [Google Scholar]

12. Reed C, Bryant R, Ibrahim AS, Edwards J Jr, Filler SG, Goldberg R, et al. Combination polyenecaspofungin treatment of rhino-orbital-cerebral mucormycosis. Clin Infect Dis. 2008 Aug 1;47(3)364-71. doi: 10.1086/589857 [Crossref] [PubMed][Google Scholar]

13. Yun MW, Lui CC, Chen WJ. Facial Paralysis Secondary to Tympanic Mucormycosis- Case Report. American Journal of Otology. 1994;15;413-414. [Crossref][PubMed][Google Scholar] 